\title{
PRÁCTICAS MORTUORIAS ENTRE LOS CAZADORES-RECOLECTORES DEL CANAL BEAGLE: EL CASO DE SHAMAKUSH ENTIERRO
}

\author{
MYRIAN ALVAREZ;, MARTÍN VÁZQUEZ" Y ERNESTO PIANA
}

\section{RESUMEN}

Durante los últimos años, las investigaciones arqueológicas sobre el registro mortuorio del área del archipiélago Magallánico-Fueguino se han incrementado considerablemente. Estos estudios pusieron de manifiesto que las prácticas mortuorias implicaron una gran diversidad de comportamientos relacionados con el tratamiento del cuerpo, el emplazamiento del entierro, el número de individuos incluidos o los artefactos dejados junto al difunto.

En este trabajo, nos focalizamos en el análisis de un contexto específico, Shamakush Entierro, localizado en la costa norte del canal Beagle. Este sitio, datado en el $620 \pm 60 \mathrm{AP}$, exhibe el contexto mortuorio más complejo y elaborado debido al trabajo invertido en la preparación del entierro y en el ajuar que acompaña al difunto tales como: puntas de arma lítica, artefactos bifaciales, filos largo retocados y artefactos óseos.

Se presentan los procedimientos metodológicos para su abordaje y se discute la importancia de este contexto en el análisis de las sociedades litorales fueguinas.

PALABRAS CLAVE: Prácticas mortuorias - ajuar - cazadores-recolectores - canal Beagle.

\section{MORTUARY PRACTICES AMONG HUNTER-GATHERERS OF THE BEAGLE CHANEL: THE CASE OF SHAMAKUSK BURIALS}

\begin{abstract}
During the last years, the archaeological research of mortuary record on the Magellan- Fuegian Archipielago has increased. These studies showed that mortuary practices implied a great diversity of behaviors in connection with body treatment, burial placement, number of individuals or artifacts left by the mourners with the bodies.

In this paper we focus on the analysis of a specific context, Shamakush burial, located on the northern coast of the Beagle Channel region. This site, dated on $620 \pm 60 \mathrm{BP}$, exhibit the more elaborate and complex mortuary context due to the labor invested on the arrangement of the body and to the

* CADIC-CONICET. B. Houssay 200 (9410). Ushuaia Tierra del Fuego. Argentina.

* Museo del Fin del Mundo. E-mails: myrianalvarez@cadic.gov.ar; vazquez_martin@speedy.com.ar; arqueologiatierradelfueg o@gmail.com
\end{abstract}


grave goods that accompanied the body: such as lithic points, bifacial artifacts, side-scrapers, and bone artifacts.

We present the analytical procedures developed to tackle this problem and we discuss the relevance of this context in the analysis of Fuegian littoral societies.

KEYWORDS: Mortuary practices - grave goods - hunter-gatherers - Beagle Channel.

\section{INTRODUCCIÓN}

Las acciones vinculadas del mundo funerario pueden concebirse como prácticas sociales (sensu Bourdieu 1977) que producen y recrean la organización social. Su abordaje resulta sumamente importante para comprender la dinámica y la trayectoria de las sociedades pasadas.

En el caso de los canoeros que habitaron la región del canal Beagle, Tierra del Fuego (definida por Orquera y Piana 2006), las prácticas funerarias habían sido estudiadas sólo a partir de unos pocos casos conocidos y con información muy dispar y fragmentaria. Recientemente, en el marco del Proyecto Arqueológico Canal Beagle, se han desarrollado tareas de prospección, excavación y análisis de los contextos mortuorios (Tessone 2003, Piana et al. 2006). A estas tareas programadas se le sumó el hallazgo fortuito de entierros resultado de la realización de obras públicas y privadas. El incremento de datos disponibles reveló una variabilidad significativa en las prácticas mortuorias. Sin embargo, las dataciones de los enterramientos son aún insuficientes y no puede efectuarse estimación alguna sobre la diacronía o sincronía de tales prácticas.

En este trabajo presentamos el caso de Shamakush Entierro, que se caracteriza por la complejidad en el tratamiento de uno de los individuos (SHE 6) -en comparación con lo documentado en la regióny la cantidad de artefactos líticos y óseos incluidos en forma de ajuar. Esos objetos son la expresión material de elecciones y decisiones de los grupos sociales que constituyen un mensaje activo para el mundo de los vivos; comprende diversas actividades de producción y consumo de recursos que incluyen aspectos económicos y simbólicos (Bender 1985; Álvarez y Fiore 1993).

Es por ello que el análisis del ajuar de SHE 6 es significativo para comprender el interjuego de esos aspectos dentro del estudio de las sociedades canoeras fueguinas (Vazquez et al. 2007). Nos focalizaremos fundamentalmente en el análisis del ajuar y del emplazamiento del cadáver. Su estudio implicó la puesta en marcha de distintas líneas metodológicas orientadas hacia el estudio del diseño del conjunto artefactual a partir de la caracterización morfométrica de las piezas y de la aplicación del análisis funcional de base microscópica que posibilita identificar los usos a los que fueron sometidos los artefactos líticos.

Los objetivos son:

- Discutir sobre diversos aspectos de las prácticas sociales involucradas con la muerte mediante el análisis de la inversión de trabajo destinada a la preparación del contexto mortuorio; que incluye la confección del conjunto lítico y la determinación del contexto de uso de los artefactos;

- Vincular los comportamientos mortuorios inferidos en Shamakush Entierro con la dinámica social de los grupos cazadores-recolectores-pescadores del canal Beagle.

Prácticas mortuorias en el canal

Beagle: antecedentes generales

La costa norte del canal Beagle fue poblada alrededor del séptimo milenio por grupos cazadores-recolectores especializados en la explotación de recursos marinos. La subsistencia se basaba en la explotación de pinnípedos, la caza de guanacos y aves, la recolección de moluscos, la pesca y el aprovechamiento ocasional de cetáceos cuando se encontraban varados en la costa (Orquera y Piana 1999a). Estos grupos presentaban una alta movilidad con reocupación recurrente de los asentamientos, lo que generó numerosas acumulaciones de desechos o conchales distribuidos a lo largo de la costa del canal Beagle. Desde los primeros asentamientos litorales, estos grupos habrían contado con algún medio de navegación mediante el cual se desplazaban por las islas y canales más australes del archipiélago 
magallánico-fueguino (ver Orquera y Piana 1999a). Cuando las poblaciones europeas comenzaron a ingresar en la región alrededor del siglo XVI la especialización en la explotación de recursos litorales aún se mantenía vigente.

Las investigaciones en la región vienen realizándose en forma sistemática y continua desde fines de la década de 1970 en el marco del Proyecto Arqueológico Canal Beagle (PACB) (ver por ejemplo, Orquera y Piana 1999a y Orquera et al. 2006); sin embargo, hasta hace poco el análisis de las prácticas funerarias era escaso. El universo total de restos esqueletarios humanos de la región, presentados en trabajos científicos, no alcanza el centenar y medio incluyendo los datos publicados, los presentados en informes inéditos y los depositados en las colecciones de distintas instituciones europeas y americanas (cf. Guichón 2000; Tessone 2003; Legoupil 1993-94; Orquera y Piana 1997; Pérez-Pérez 1996; Aspillaga et al. 1999; Guichón et al. 2001; Ocampo et al. 2001). La mayoría de ellos proviene de hallazgos fortuitos o excavaciones no arqueológicas por lo que el registro sistemático de contextos mortuorios es bajo y el conocimiento sobre ajuares asociados es mínimo.

La presencia de ofrendas en entierros en el canal Beagle estaba documentada arqueológicamente sólo en el Sitio C130 localizado en la isla Navarino (Ocampo et al. 2001) y en Harberton Cementerio (Kozameh et al. 2002; Piana et al. 2006). En el primer caso, el ajuar estaba compuesto por un punzón o lezna de hueso y un conjunto de lascas halladas junto a un esqueleto humano fechado en $490 \pm 30 \mathrm{AP}{ }^{14} \mathrm{C}$ no cal. En el segundo caso, se trata de una lasca y dos raspadores de vidrio que ubican el entierro en el período etnohistórico. Sin embargo, es posible que la frecuencia de la inclusión de ajuar pueda estar afectada por la destrucción post-depositacional de implementos confeccionados con materiales perecederos. Dentro de los contextos de grupos cazadores-recolectores litorales que ocuparon la porción occidental de los canales magallánico-fueguinos, los casos de entierros con ajuar son más numerosos. Entre las ofrendas recuperadas se destacan materiales perecederos tales como maderas, cueros y cestería así como restos de arpones, cuentas de valva y artefactos líticos (ver entre otros Aspillaga y Ocampo 1996; San Román y Morello 2001; Prieto y Cárdenas 2001).
En la información etnohistórica son numerosas las menciones que indican que amortajar los cuerpos con cueros, trapos, vestimentas viejas $u$ otros elementos era una práctica generalizada entre los Yámana (ver por ejemplo, Bridges 1886:209; Hyades 1887:332; Gusinde 1937:1076-1077; Orquera y Piana 1999 b: 456; van de Maele 2000; Tessone 2003). La inclusión intencional de bienes, en cambio, no parece haber sido una actividad regular, sólo fue señalada en algunas oportunidades (Gusinde 1937: 1081 y 1951:331-332; Tessone 2003: 54 y bibliografía allí citada); en los casos mencionados el ajuar consistía en algunas pertenencias personales del difunto. Más aún, en algunos escritos se afirma que cuando una persona moría sus bienes personales eran quemados o arrojados al mar (Orquera y Piana 1999b).

Los datos arqueológicos muestran una importante diversidad en las prácticas relacionadas con el mundo funerario de las poblaciones que habitaron la región. La mayoría de los casos excavados hasta el momento provienen de la costa norte del canal Beagle, a los que deben sumarse algunos provenientes de Navarino y las Islas Wollaston. Se detectaron por ejemplo:

a) individuos masculinos y femeninos, desde párvulos hasta individuos seniles;

b) diversas formas de disponer los cadáveres (flexionados, estirados de cubito dorsal, todos primarios);

c) distintos tipos de espacios seleccionados para la disposición de los cuerpos (concheros, aleros, inhumaciones en tierra a cielo abierto);

d) cantidades variables de individuos por locus (mayoritariamente individuales hasta casos de concentración de 5 individuos);

e) con y sin preparación previa del espacio o del cuerpo (amortajados, cremaciones) o ajuares asociados (mayoritariamente sin ajuar asociado, con unos pocos elementos y un caso con ajuar complejo) (Tessone 2003; Piana et al. 2006: tabla 1;).

No se ha verificado una correlación positiva entre las distintas variables: individuos de la misma edad o género fueron hallados con diversas formas de disposición y en tipos de espacios diferentes. Las dataciones disponibles se restringen a los últimos 1.500 años. 
Shamakush Entierro: emplazamiento y características generales

Shamakush Entierro se encuentra localizado en el sector central de la costa norte del canal Beagle sobre un tramo de costa que se conoce actualmente con el nombre de Puerto Remolino (Figura 1). En una franja costera de unos $2,5 \mathrm{~km}$ se detectó más de una veintena de conchales de origen antrópico (Figura 2) de los cuales fueron excavados Shamakush I, X (Orquera y Piana 1999a) y VIII (Piana y Vázquez 2005) y Mischiúen I (Piana et al. 2004). También se excavó un enterratorio, Mischiúen III (Vila Mitja 2004) y el emplazamiento de la choza en que se realizó el último paso iniciático con la presencia de Gusinde (Vila et al. 2002).

En un afloramiento de la Formación Yagan que forma un pequeño cerro, se halló un alero $\left(54^{\circ}\right.$ $51,56^{\prime} \mathrm{S}$ y $67^{\circ} 51,70^{\prime} \mathrm{O}$ ) en el que obtuvieron restos esqueletarios de varios individuos. El alero se halla a $670 \mathrm{~m}$ de la costa y a 5 m.s.n.m. Los primeros restos humanos provenientes de este sitio fueron descubiertos casualmente por un caminante en 1994. El yacimiento había sido perturbado superficialmente: se hallaron restos de fogatas recientes y un pozo de unos $40 \mathrm{~cm}$. de diámetro parcialmente relleno con sedimento removido. Varios restos óseos, entre ellos huesos largos y un cráneo, quedaron al descubierto dispersos en la superficie o parcialmente cubiertos por hojarasca o sedimento suelto. Esta situación justificó una intervención expeditiva, realizada en febrero de ese mismo año, a fin de recuperar el material expuesto y evitar así su perdida total.

Posteriormente, en el año 2003, como parte de un programa de prospección y sondeos sistemáticos con el propósito de localizar y excavar contextos mortuorios (Piana et al. 2006), se retomaron las tareas de excavación en este sitio a fin de verificar la existencia de otros restos. Como resultado de estas tareas se recupero una importante cantidad de restos en posición sub-superficial, además de otros en posición estratigráfica que incluyen un cuerpo en posición primaria.

El alero de Shamakush Entierro está emplazado sobre la ladera del cerro; tiene poca profundidad, unos seis metros de largo y está relativamente cerrado por bloques de derrumbe. A unos 300 metros, sobre la misma ladera rocosa, en otro alero (Mischiúen III), fue hallado contexto funerario que contenía dos individuos (Tessone 2003; Vila Mitja 2004) (Figura 2).

En total se excavó un área de $14 \mathrm{~m}^{2}$ bajo el alero. El conjunto recuperado en la parte superior de este depósito, incluyendo las intervenciones de 1994 y 2003, está conformado por un mínimo de cuatro individuos. Estos corresponden a dos individuos femeninos adultos (SHE 1 y SHE 2), un adulto masculino (SHE 3) y un subadulto de sexo no determinado del que se recuperaron escasos restos (SHE 4) (Tessone 2003; Piana et al. 2006; Vázquez et al. 2007). Hacia la parte basal del depósito fueron hallados restos de dos individuos, uno de ellos representado solo por unos pocos elementos que podrían corresponderse con alguno de los individuos mencionados arriba (SHE 5) y otro individuo, el único en posición articulada, adulto masculino (Tessone com. pers.) denominado: Shamakush Entierro Individuo 6 (SHE 6). Cabe aclarar que esta nomenclatura responde a la secuencia de excavación y no a la cuantificación anatómica de los restos, que hasta el momento preferimos mantener en cinco individuos.

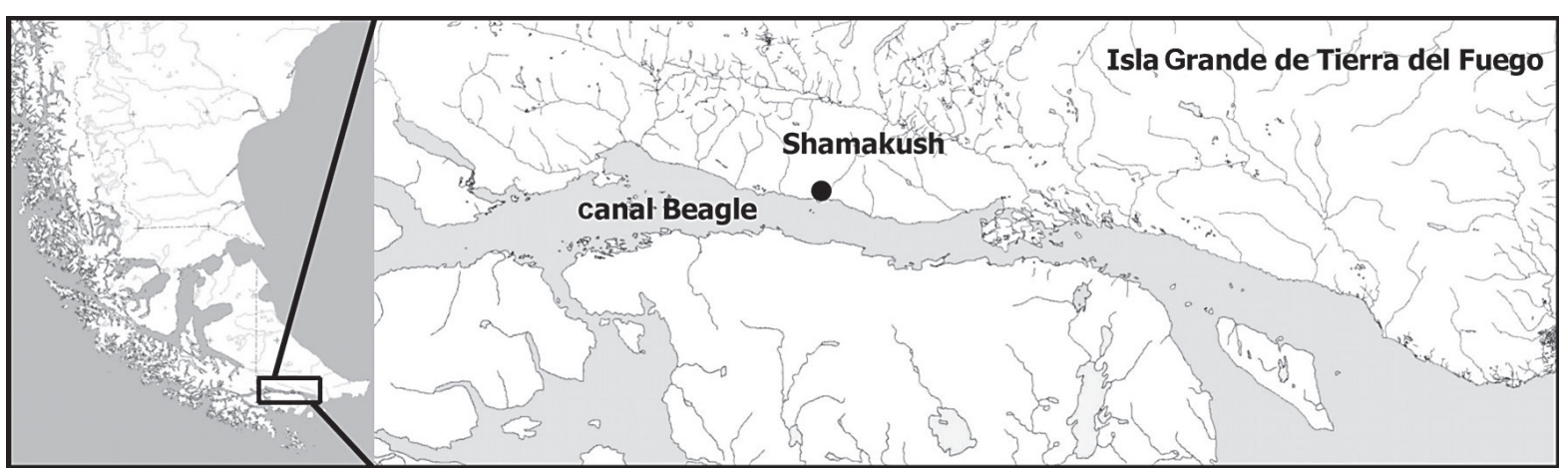

Fig. 1. Mapa de ubicación del sitio. 


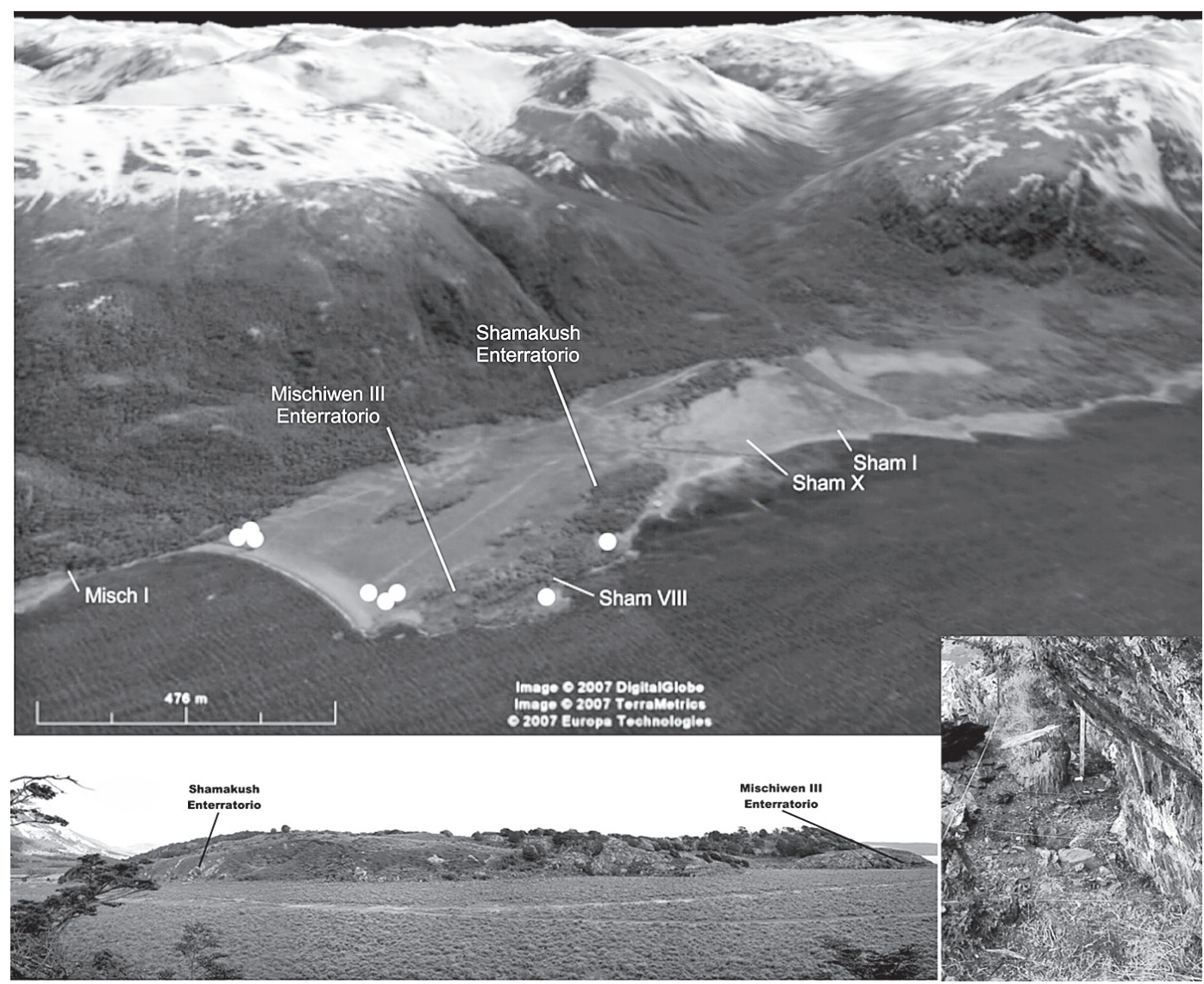

Fig. 2. Arriba: Localización de Shamakush Entierro y otros sitios arqueológicos relacionados. Abajo: Vista del afloramiento rocoso y emplazamiento de Shamakush Entierro y Mischiwen III y vista del interior del abrigo.

En el conjunto superior se registraron unas pocas unidades óseas anatómicamente articuladas. La gran mayoría de huesos pertenecientes a los cuatro individuos estaban completamente mezclados y su distribución horizontal era bastante restringida. La mayor densidad de restos fue hallada en centro del alero en unos $3 \mathrm{~m}^{2}$. Todos los elementos fueron recuperados o bien en la denominada capa A (sedimento poco compactado, hojarasca y fragmentos de roca de caja disgregada) o bien en superficie. El estado de conservación de los huesos es variable y algunos de ellos presentan signos de combustión. En un primer momento se consideró la posibilidad que estas termoalteraciones fuesen producto de fogatas recientes encendidas sobre los huesos en posición superficial o subsuperficial. Sin embargo, el análisis llevado a cabo por la Lic. Livia Kozameh (en Tessone 2003: 71) reveló que los elementos que presentan signos de combustión correspon- derían a un mismo individuo (SHE 1); de esto se desprende que la termoalteración, sea producto de una cremación intencional o de alguna quemazón incidental, afectó a los restos de un único individuo antes de su dispersión y consecuente mezcla de los elementos.

Fueron hallados sólo unos pocos elementos artefactuales en la capa A y su asociación con el conjunto óseo no es segura. Se recuperaron una lasca, unas cuentas de collar en hueso de ave en sectores periféricos a la concentración de huesos y un núcleo con unas pocas extracciones. Respecto de este último, no es posible sostener una asociación segura con los eventos de inhumaciones. Sin embargo, es posible afirmar que fue transportado hasta el alero, ya que la materia prima difiere de la roca de caja. El nódulo presenta rasgos de acarreo fluvial y su gran tamaño no se condice con los depósitos de paleoplaya marina adyacentes; los depósitos más 
cercanos con guijarros de este tipo se encuentran en el cauce o paleocauces del río Remolino.

Debajo de esta capa superficial (Capa A) se disponía una capa compuesta por sedimento negruzco y rocas de caja de tamaño muy variable (Capa B). Esta capa era arqueológicamente estéril a excepción de los restos hallados en su parte basal. Allí, prácticamente en contacto con la roca de caja subyacente o con sedimento de origen eólico de color amarillento (capa $\mathrm{C}$ ), fueron hallados restos humanos de dos individuos. Uno de ellos (SHE 6), en posición primaria, se encontraba decúbito dorsal y presentaba la pérdida de ciertas regiones anatómicas. Las porciones en mejor estado de preservación relativo eran la cabeza, el tórax, la región lumbo-pélvica y se encontraban en posición articulada. El resto de las porciones anatómicas habían desaparecido en forma total o parcial: en la zona donde deberían haber estado los fémures, fueron hallados fragmentos de huesos calcinados, muy fragmentados, el brazo derecho estaba casi totalmente ausente a excepción del húmero proximal en posición anatómica y el brazo izquierdo, aunque mejor preservado, se encontraba fragmentado ( $\mathrm{Fi}-$ guras 3 y 4). Del otro individuo (SHE 5) sólo fueron recuperados el húmero, el omóplato y la clavícula izquierdos, además de una vértebra cervical y el atlas, que potencialmente podrían corresponderse con alguno de los individuos del conjunto superior. Hacia la sección sur de la excavación fueron hallados las diáfisis de dos tibias y fragmentos de peronés en posición subparalela, pero dada su ubicación en relación a los demás restos, aún es incierta la correspondencia entre éstas y uno u otro individuo (Figuras 3 y 4).

Sin lugar a dudas el aspecto más llamativo del contexto mortuorio de SHE 6 es el ajuar asociado, hasta el momento el más complejo registrado en la región. Este ajuar esta compuesto por dieciséis puntas de arma, halladas agrupadas y superpuestas entre sí, a la altura media del tórax, del lado derecho (Figuras 3 y 4). La agrupación de estas puntas en un sector tan reducido, su posición horizontal y la escasa cantidad de sedimento intersticial entre ellas conducen a suponer que deben haber sido depositadas dentro de algún tipo de contenedor confeccionado en material perecedero. Unos pocos centímetros hacia el sur, a la altura de la región lumbar del cuerpo, fue hallado un alisador pasivo sin formatización aparente, pero con signos de abrasión visibles en ambas caras. También del lado derecho del cuerpo, a la altura de la región pélvica y de la zona que hubieran ocupado los fémures, se encontraba un conjunto de artefactos bifaciales, filos largos retocados (o raederas sensu Orquera y Piana 1986) y un guijarro alargado sin modificación aparente que, por su relación con las otras piezas y por ser de roca alóctona interpretamos como parte del ajuar. El resto del conjunto se completa con otro filo largo retocado ubicado bajo la cabeza del lado derecho, un punzón confeccionado sobre metapodio de guanaco situado sobre el lado izquierdo del cráneo,

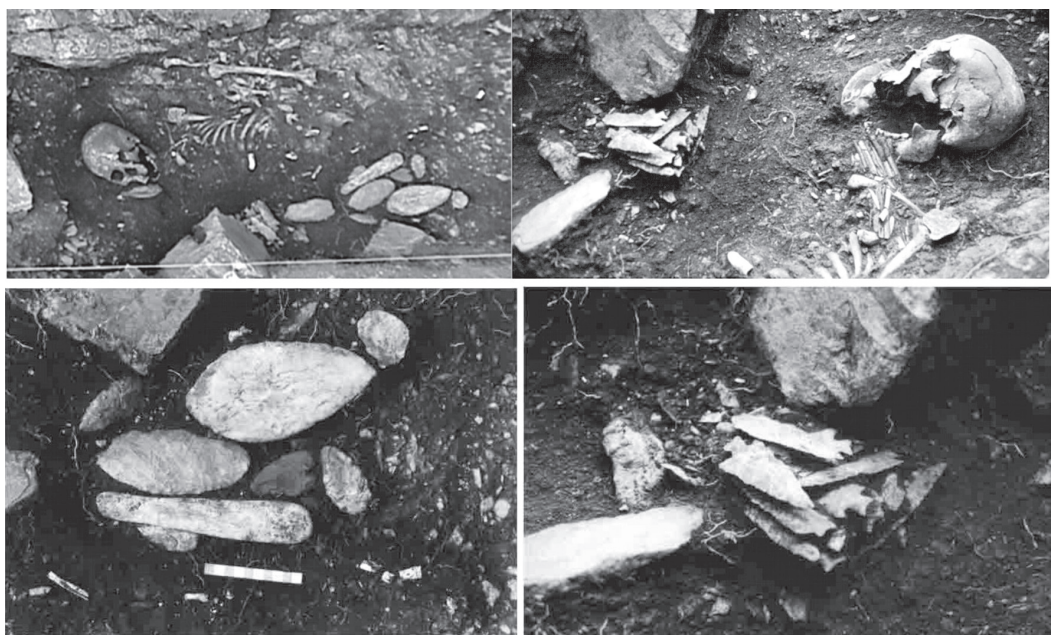

Fig. 3. Excavación de Shamakush Entierro individuo 6: arriba vista general y detalle de disposición del cuerpo y ajuar. Derecha abajo: detalle de la disposición del ajuar. Izquierda abajo: detalle del conjunto de puntas. 


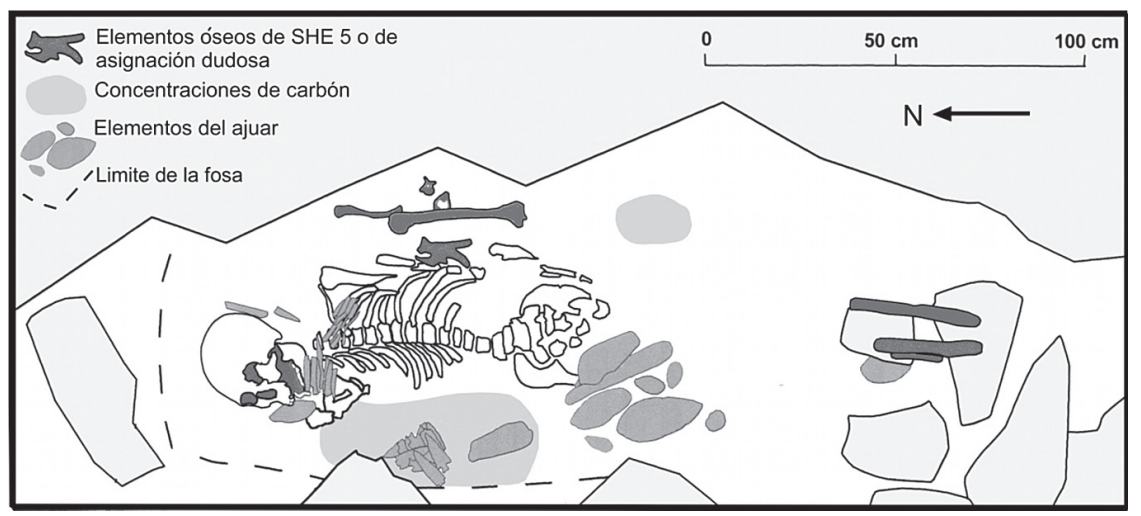

Fig. 4. Planta de excavación de Shamakush Enterratorio 6

un conjunto de diáfisis de hueso de ave decoradas, que sin dudas corresponden a algún tipo de collar ya que estaban dispuestas en forma subparalela entre sí, sobre el cuello y el hombro izquierdo del cuerpo y un filo largo retocado unifacialmente ubicado casi en contacto con las diáfisis de las tibias mencionadas. Esta última se incluye en el análisis del conjunto desarrollado mas adelante, aunque su asociación con el resto de los artefactos no es segura dada la incertidumbre derivada de la posición relativa de las tibias respecto de SHE 6.

Otro aspecto interesante de este contexto es la presencia de signos y restos de combustión en diversos sectores. El cráneo sobre la región facial y temporal izquierda, que es la zona que estaba en posición más superficial, y parte de la mandíbula, presentaban coloraciones que iban del negro al rojizo; asimismo algunas cuentas de collar también presentaban termoalteraciones. Otras regiones que presentaban signos de combustión son el hombro derecho y la pelvis. El resto del esqueleto no tenía señales de termoalteración intensa, salvo la existencia de fragmentos de hueso calcinado hallados en la zona donde deberían haber estado los fémures. Sobre el lado derecho del cuerpo, en el lugar que debería haber sido ocupado por el brazo, fue recuperada una importante concentración de carbón. Incluso dentro de ésta se recuperaron algunos segmentos de ramas que aun conservaban su estructura leñosa. Un fechado efectuado sobre una muestra proveniente de esta concentración, indicó una antigüedad de $620 \pm$ 60 años ${ }^{14} \mathrm{C}$ AP (AC 1680). Otra concentración de carbones, de extensión más reducida fue registrada sobre el lado izquierdo del cuerpo a la altura de los fémures. Por último hay que mencionar una pequeña concentración de restos carbonizados cuya estructura no parecía ser leñosa y que fueron hallados en la zona del cuello y bajo la mandíbula.

Hay que destacar que ninguno de los artefactos líticos hallados presenta rastros de daño térmico, ni tampoco fueron registrados manchas de sedimento termoalterado; en cambio sí fueron halladas algunas rocas, dentro de la capa $\mathrm{B}$ que podrían haber sido sometidas a calor.

Por ultimo, existen claras evidencias de la preparación del espacio donde fue inhumado el cuerpo y el ajuar asociado. En primer lugar, la posición de este individuo es de por sí muy profunda, (en relación al resto de los huesos hallados), entre 30 y $50 \mathrm{~cm}$. por debajo de la superficie y en contacto directo con la roca base o con una delgada capa de sedimento eólico (Capa C). En segundo lugar, se registró un claro corte en la continuidad de la Capa $\mathrm{C}$, rodeando la cabeza y el costado derecho del cuerpo hasta la zona pélvica en la posición donde se halló parte del ajuar. La concentración de carbón y el conjunto de puntas mencionados estaban prácticamente limitados por este "escalón" conformado dentro del sedimento de Capa C; esta depresión donde se encontraba dispuesto el cuerpo y el ajuar se hallaba rellena con sedimento de la Capa B. Hacia el sector que habría sido ocupado por las piernas no pudo determinarse con seguridad la existencia de esta discontinuidad en la Capa C. Este rasgo y su disposición respecto de los restos es interpretado como producto de la preparación del espacio del alero mediante la excavación de una fosa, dentro de la cual fue inhumado un cuerpo y depositado el ajuar. También se verifico la existencia de rocas de caja incluidas dentro del sedimento de Capa $\mathrm{B}$, si bien es posible que hayan 
sido dispuestas intencionalmente en esa posición para cubrir el cuerpo, tampoco es posible descartar que su presencia se deba a derrumbes del techo y pared del alero.

Hasta el momento Shamakush Entierro es la localidad donde se ha verificado la mayor concentración de entierros humanos. Consideramos como hipótesis más probable que la inhumación de estos cuerpos no debe haber sido simultánea, no obstante la secuencia relativa o la diacronía -sincronía de estos eventos aún es materia de discusión. Por el momento consideramos tres alternativas de interpretación posibles para dar cuenta de esta secuencia y explicar parte de la historia tafonómica de este alero.

La primera tiene en cuenta una secuencia en la cual SHE 6 seria el primero de los individuos inhumados en el alero, luego el espacio seria reutilizado para la depositación de otros cuerpos y la sucesión de estas actividades habrían alterado parcialmente a SHE 6, implicando la perdida y mezcla de elementos. Si esta interpretación fuera acertada las termoalteraciones que afectaron ciertos sectores de SHE 6 podrían deberse a eventos posteriores que terminaron incidiendo sobre el cuerpo ya enterrado.

En la segunda interpretación, SHE 6 no seria la inhumación más antigua, sino un evento posterior que alteró la disposición los cuerpos enterrados previamente en este alero. La preparación de una fosa para disponer el cuerpo y el ajuar, habría alterado la posición de los restos previamente enterrados y su relleno con el sedimento removido implicó la mezcla de los huesos de los otros 4 individuos.

En la tercera posibilidad, independientemente de la secuencia relativa de entierros o la potencial sincronía, procesos post-depositacionales habrían alterado casi la totalidad del depósito, con excepción de su parte más profunda donde se halló SHE 6 y su ajuar asociado. Tales alteraciones podrían haber sido causadas por derrumbes, ocupaciones posteriores del alero, actividad de animales, etc. Recordemos que fueron registradas alteraciones relativamente recientes en la superficie del alero (fogatas y un pozo).

Por el momento, sólo se cuenta con un fechado radiocarbónico procedente de una muestra de carbón asociada al ajuar del SHE 6, sería necesario realizar una batería de nuevos fechados sobre los restos óseos para evaluar la secuencia relativa de entierros de los distintos individuos. Por otro lado, también será imprescindible efectuar un estudio tafonómico profundo del conjunto antes de inclinarse por alguna de estas hipótesis o alguna combinación de ellas.

\section{ANÁLISIS DEL AJUAR: MÉTODOS Y RESULTADOS}

Consideramos que la tecnología es un fenómeno total (sensu Mauss 1967, cit. por Schlanger 1994) en cuyo desarrollo intervienen factores económicos, políticos y simbólicos (Álvarez y Fiore 1993). Estos aspectos influyen en todas las esferas productivas de una sociedad y presentan dimensiones tangibles a partir de las decisiones y elecciones de los grupos, así como a través de la organización espacial y temporal de las actividades técnicas (Álvarez 2003). El caso del ajuar de Shamakush entierro por el propio contexto de depositación, abría la posibilidad de evaluar en forma concreta y contrastable la interacción de esos niveles dentro de la esfera de producción tecnológica desarrollada por los grupos cazadores-recolectores-pescadores de la costa norte del canal Beagle.

Para ello se pusieron en marcha distintas líneas de análisis complementarias, orientadas hacia la determinación de:

- la inversión laboral destinada a la producción de objetos incluidos en la inhumación;

- el contexto de uso de los artefactos: que incluía no sólo su utilización como bienes que acompañan al difunto sino también su eventual utilización previa como objetos de trabajo;

- la relación entre éste conjunto con los recuperados en los contextos domésticos.

\section{a) Métodos analíticos}

La inversión de trabajo se determinó a partir del valor de producción del conjunto artefactual medido a través de la cantidad de operaciones y técnicas necesarias para la manufactura del instrumento (que incluye desde el aprovisionamiento de las materias primas hasta los procedimientos necesarios para su manufactura), la cantidad y calidad de los instrumentos participantes en los procesos de transformación, el grado de conocimiento y 
habilidades cognitivo-motrices puestas en marcha para su obtención (Álvarez 2003). Para su análisis se efectuaron los estudios morfo-métricos de los artefactos de acuerdo a los criterios establecidos por Orquera y Piana (1986); para el análisis de las piezas bifaciales se consideraron las variables propuestas por Aschero y Hoscsman (2004).

El contexto de uso se refiere a la articulación entre el material procesado (características y estado), la cinemática del trabajo; el ordenamiento espaciotemporal de la actividad en la cual éste participa, su periodicidad y los conocimientos relacionados con el desarrollo de esa tarea. Este concepto es más amplio y abarcativo que el término "función" que alude por lo general simplemente a la finalidad de determinada herramienta (cortar, raspar); implica además una visión de la tecnología concebida como fenómeno total que incluye múltiples dimensiones y en la que la gestión del espacial y temporal de las actividades de producción-consumo no pueden ser ignoradas (Álvarez 2003). La determinación del uso fue realizada en base a los criterios y procedimientos establecidos por el análisis funcional de base microscópica, siguiendo el modelo de formación de rastros de uso sobre rocas de granulometría gruesa y formaciones cristalinas (Mansur 1999). Para su observación e identificación se utilizó un microscopio de reflexión Olympus BHSM con objetivos y oculares que permiten aumentos de 50x, 100x, 200x y 500x. Para la asignación funcional de las puntas de arma se tomaron los criterios establecidos por Ratto (2003).

La comparación entre los conjuntos procedentes de contextos domésticos con los del ajuar incluido en la inhumación tenía un doble propósito. En primer lugar, se buscaba comenzar a dilucidar las vinculaciones existentes entre la esfera de las actividades domésticas y la esfera de los comportamientos mortuorios a fin de obtener un panorama amplio de las estrategias de producción y reproducción social dentro de la dinámica de los grupos cazadores-recolectores canoeros. En segundo término, se intentaba dilucidar cuáles fueron las actividades implicadas en las prácticas mortuorias y si los objetos incluidos en la inhumación exhibían diseños y/o usos diferentes a los recuperados en contextos domésticos.

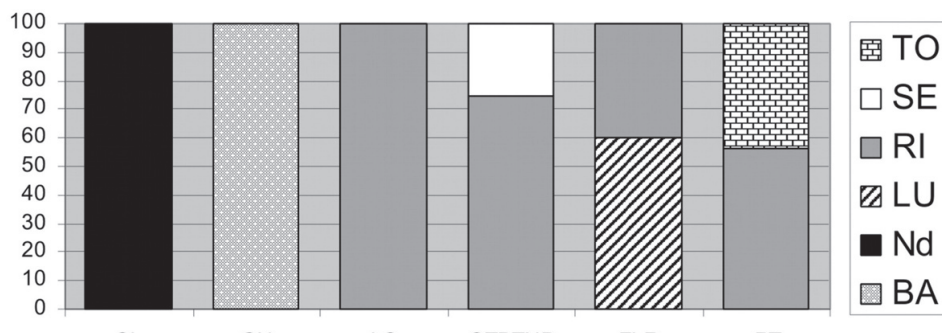

CL

GU

LS

OTBTND

FLR

PT

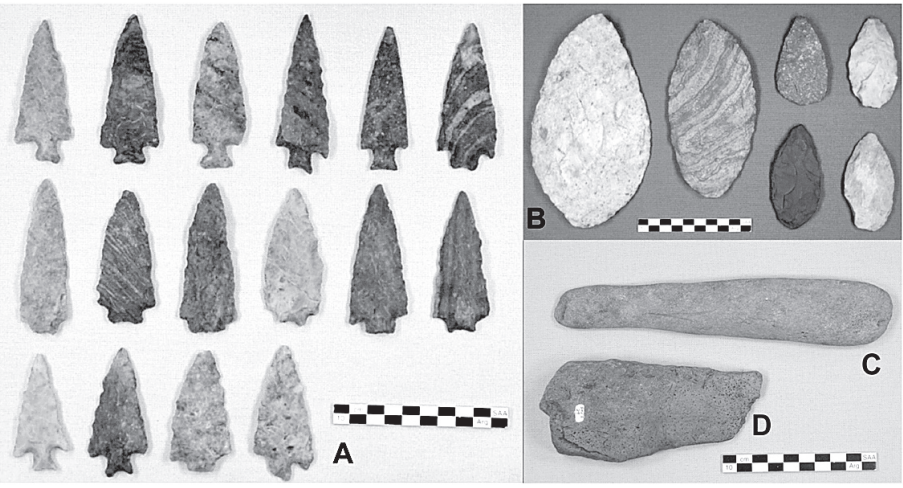

Fig. 5. Arriba: distribución de materias primas por grupo tecno-morfológico. Abajo: piezas destacadas del ajuar asociado a SHE 6; A) Puntas de arma, B) Artefactos bifaciales y filos largos retocados, C) Guijarro alargado, D) Clasto con evidencias de abrasión.

Referencias: TO: toba de grano fino; SE: sedimentita; RI: riolita; LU: lutita; Nd: no diferenciada; BA: basalto; CL: clasto; GU: guijarro; LS: lasca; OTBTND: objeto de talla bifacial de tipo no determinado; FLR: filo largo retocado; PT: puntas. 


\section{b) Análisis de los materiales}

El conjunto artefactual lítico tallado se compone de 27 piezas entre las que se identificaron puntas de arma $(\mathrm{N}=16)$, artefactos bifaciales $(\mathrm{N}=5)$, filos largos retocados $(\mathrm{N}=4)$, lascas $(\mathrm{N}=2)$. Todos ellos fueron manufacturados con rocas volcánicas de tipo piroclástico metamorfizadas y sedimentitas pertenecientes a la Formación Lemaire que aflora en la Cordillera Fueguina. Estas rocas constituyen los materiales más utilizados por las sociedades cazadoras recolectoras-pescadoras del canal Beagle que alcanzan a más del $90 \%$ de las materias primas explotadas a lo largo de toda la secuencia (Álvarez 2003; Terradas 1996). Su aprovisionamiento se realizaba en depósitos secundarios generados por los procesos de erosión fluvio-glaciar del Cuaternario. Entre las metamorfitas se seleccionaron riolitas, tobas de grano fino y lutitas (Figura 5). Se recuperaron además un guijarro y un alisador pasivo. Ejemplares de este último fueron recuperados en distintos sitios del canal (Orquera y Piana 1999a).

En lo que respecta a las actividades de gestión de materias primas, la reducción bifacial de soportes constituye el procedimiento técnico más utilizado para la confección del conjunto lítico. Esta técnica si bien está presente desde los momentos tempranos de ocupación de la región, experimenta un aumento considerable a partir del 4.000 AP asociada con la aparición de puntas de arma y posteriormente se mantiene en frecuencias importantes, con algunas fluctuaciones por sitio (Álvarez 2007a). No obstante, en el marco de las ocupaciones tardías, el conjunto lítico de SHE 6 es un ejemplo singular dado que el índice de bifacialidad alcanza al 77,78\% (Figura 6).

Otro de los aspectos que llamó la atención de este conjunto fue el tamaño de las piezas respecto de las dimensiones características de las mismas clases de implementos presentes en los conjuntos instrumentales provenientes de contextos domésticos del registro arqueológico de la costa norte del canal Beagle (Figura 7). La mayor parte de los artefactos que conforman el ajuar presenta tamaños grandes (> $80 \mathrm{~mm}$ ) o muy grandes (> $120 \mathrm{~mm}$ ). Por el contrario, tal como muestra el gráfico de dispersión ilustrado en la figura 7, los conjuntos líticos hallados en sitios domésticos se componen mayoritariamente de piezas de tamaño mediano (entre 40 y $80 \mathrm{~mm}$ ). Los valores

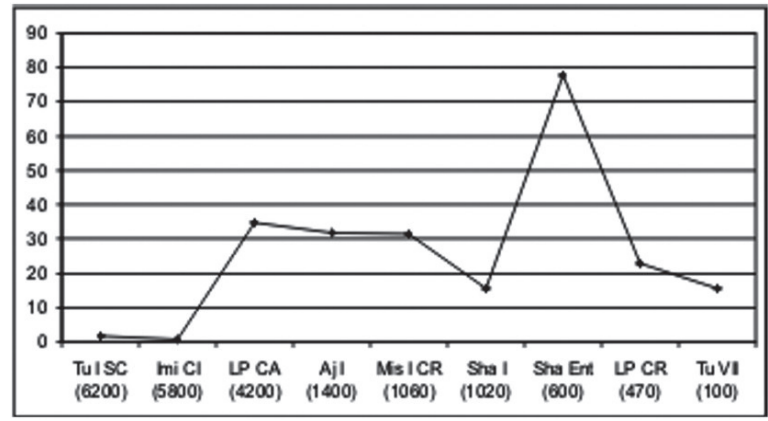

Fig. 6. Índice de bifacialidad a los largo de la secuencia de ocupación del canal Beagle.

Referencias: Tu I SC: Túnel I Segundo Componente; Imi CI: Imiwaia Concheros Inferiores; LP CA: Lancha Packewaia Componente Antiguo; Mis I CR: Mischiúen I Componente Reciente; Sha I: Shamakush I; Sha Ent: Shamakush Entierro; LP CR: LP CA: Lancha Packewaia Componente Reciente; Tu VII: Túnel VII.

Nota: entre paréntesis se consignan los fechados de cada sitio sin sigmas de error por cuestiones de espacio.

medios, en lo que respecta fundamentalmente al largo de las piezas, exhiben diferencias estadísticamente significativas si se compara el conjunto incluido en la inhumación con las piezas procedentes de los sitios de actividades múltiples (Figura 8). El módulo de espesor es en todos los casos fino. Los tamaños más grandes en este conjunto se distribuyen entre las piezas bifaciales y los filos largos retocados; las dos lascas que formaban parte del conjunto son de tamaño mediano.

La obtención de soportes de grandes dimensiones debió requerir una mayor inversión laboral teniendo en cuenta las propiedades y las características litológicas de las metamorfitas locales. Por lo

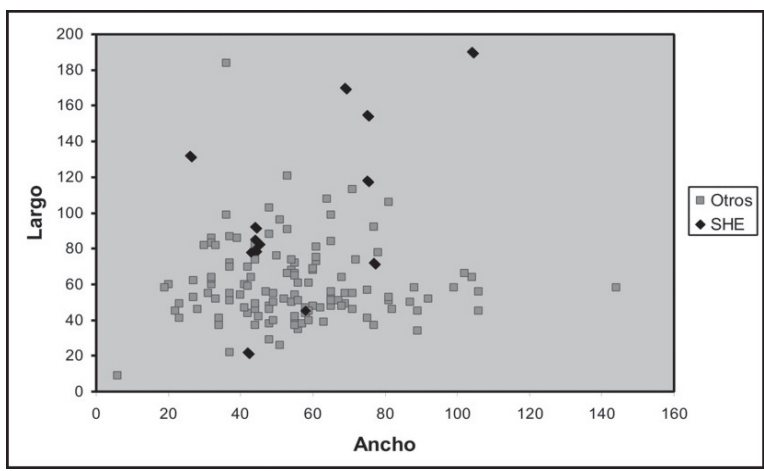

Fig. 7. Diagrama de dispersión de las características dimensionales de los artefactos del ajuar y de los contextos domésticos. 

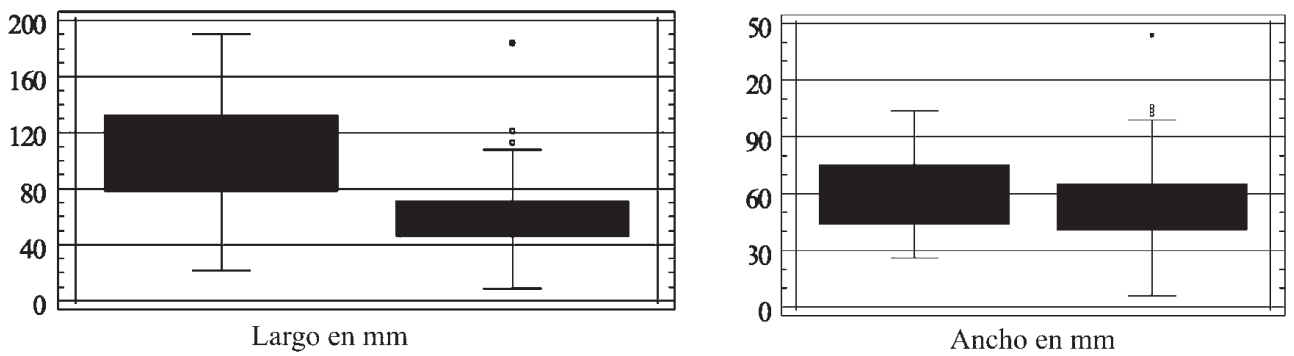

Fig. 8. Grafico de caja y bigote de los largos y anchos comparativos de los artefactos del ajuar con los de los sitios domésticos del canal Beagle.

general, los nódulos presentan planos internos de cizallamiento que disminuyen la cantidad de material potencialmente utilizable por clasto, ya que se fractura de un modo no previsible. En consecuencia, la obtención de soportes de gran tamaño ya sea para la posterior formatización de los filos o para su reducción bifacial debió requerir una inversión laboral notable.

La composición del ajuar guarda similitudes con los artefactos que por lo general se encuentran en contextos domésticos. Se compone, como vimos, de filos largos retocados, lascas, puntas de arma $y$ artefactos bifaciales. Es llamativa la ausencia de raspadores, aunque también en el sitio Ajej I (1.400 $\mathrm{AP})$ no fueron hallados este tipo de instrumentos (Piana et al. 2007 y 2008). Lo que resulta más notable en el ajuar es la distribución de frecuencias de los artefactos dentro del conjunto. A diferencia de lo que ocurre en la mayoría de los sitios, las puntas y los artefactos bifaciales son cuantitativamente dominantes.

Los diseños tecno-morfológicos identificados, no obstante mantienen las mismas tendencias que el resto de los conjuntos. Los filos largos retocados aparecen en todas las ocupaciones de la costa norte del canal Beagle en frecuencias importantes. Los que forman parte del ajuar presentan bordes convexos con retoques ultramarginales escamosos y paralelos. Sobre un total de cuatro: 3 son filos simples y uno es doble. Dos son de tamaño considerable mientras que las dos restantes mantienen las mismas características dimensionales que el resto de los conjuntos (ver Figuras 5 y 7 ).

En cuanto a los artefactos bifaciales el análisis morfo-técnico reveló algunas diferencias a nivel intragrupo. Todos fueron formatizados mediante retalla y los negativos de lascado no llegan al centro de la pieza. Del mismo modo que ocurre con los filos largos retocados, uno es de tamaño mediano, dos son de tamaño grande y dos muy grandes (ver Figura 5). Los tres de mayores dimensiones exhiben además el filo regularizado mediante retoques, tienden a una mayor simetría, presentan contornos regulares y tienen un espesor relativo (en relación al tamaño general de la pieza) menor que el resto de este conjunto. Los dos artefactos bifaciales restantes, no están regularizados; uno presenta una fractura lateral y ambos exhiben accidentes de talla. Presentan lascados con terminaciones reflejadas (o en forma de "charnela") que posiblemente dificultaron la reducción posterior del soporte.

Los artefactos bifaciales en la costa norte del canal Beagle (excluyendo a las puntas de arma) presentan escasa diversidad: sólo se identificaron filos largos retocados bifaciales (o "raederas bifaciales" sensu Orquera y Piana 1986) y objetos de talla bifacial de tipo no determinable. El aumento de éstos últimos a lo largo de la secuencia está estrechamente vinculado con el incremento en las puntas. Es por ello que se propuso como hipótesis que dichos artefactos serían producto de los estadios de formatización de puntas, hecho que fue corroborado mediante el análisis funcional de base microscópica ya que al menos en dos conjuntos analizados ninguna pieza presentaba rastros de utilización (para una discusión más detallada ver: Álvarez 2007a). Por el contrario, los filos largos retocados fueron utilizados, en la totalidad de casos analizados, para acciones de corte sobre hueso (Álvarez op. cit.).

En el caso de artefactos incluidos en el ajuar los dos de tamaño más pequeño podrían tratarse de preformas producto de la manufactura de instrumentos. No obstante, los de mayor tamaño presentan, tal como se dijo, características morfológicas que 


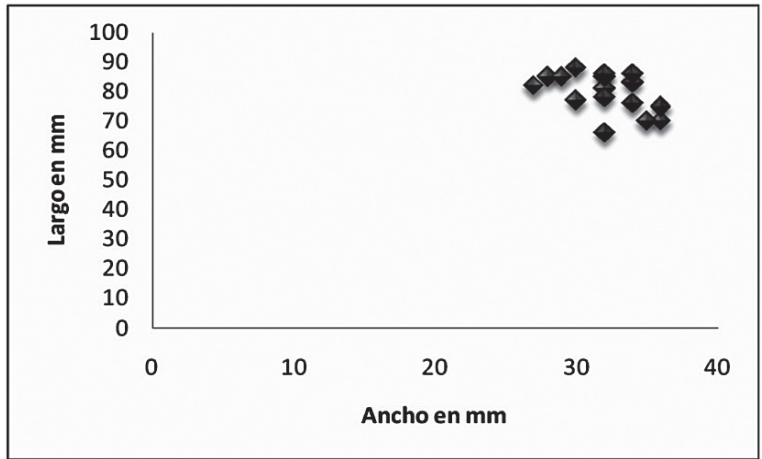

Fig. 9. Diagrama de dispersión de las características dimensionales de las puntas de arma.

permiten presuponer que se trataría de artefactos terminados, comparados con otros instrumentos conocidos en la región bajo estudio.

Las puntas de arma son pedunculadas, de limbo triangular, aletas rectas, de tamaños medianos (entre $40-80 \mathrm{~mm}$ ) y grandes $(80-120 \mathrm{~mm}$ ) y exhiben cierta homogeneidad morfológica (ver Figuras 5 y 9). Todos los artefactos se encuentran enteros y el peso oscila entre 9 y 25 gramos con una media de 17 gramos (Figura 10 y Tabla 1). Los limbos presentan superficies muy grandes (Figura 11) y bajo índice de refuerzo. La superficie de refuerzo refleja los esfuerzos mecánicos que soporta el sistema técnico y se mide a través de la relación espesor/ancho y de la tenacidad de la roca (Ratto 2003). En este caso la tenacidad de la roca es constante dado que se trata de un mismo material.

El ancho del pedúnculo, que indica el sistema de enmangamiento del arma, se distribuye en un rango que va entre los 14 y $20 \mathrm{~mm}$ (Figura 12); el ancho de los astiles de las flechas no excede los 10 mm (Ratto 2003). Para la evaluación de la aerodinámica de las puntas se consideró la forma de la sección, la simetría del limbo y la superficie de contacto con aire; estas variables permitieron

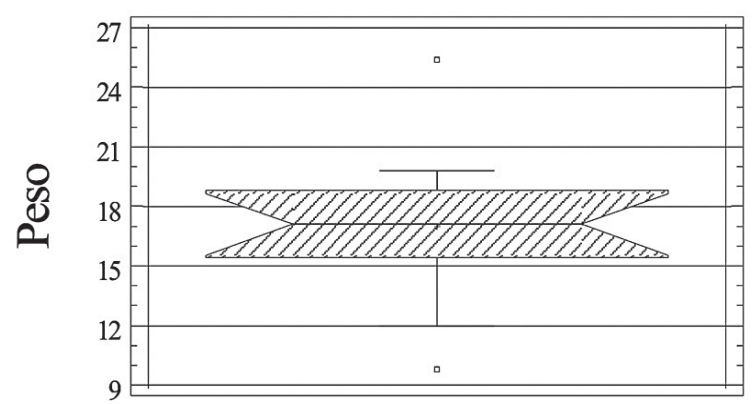

Fig. 10. Gráfico de caja y bigote de los pesos de las puntas de arma.

determinar que todas las puntas presentan aerodinámica imperfecta.

El análisis del ángulo en vista plana indica la capacidad de penetración de una punta en la presa (Tabla 1). La información actualística revela que las puntas de flecha presentan ángulos en vista plana inferiores a $45^{\circ}$ mientras que aquellas piezas con valores superiores a $56^{\circ}$ son ineficientes en cualquiera de los sistemas técnicos considerados (Ratto 2003). Estos diseños de puntas aparecen en los sitios arqueológicos del canal Beagle con posterioridad al 2.000 AP (Orquera y Piana 1999a).

En lo que respecta al contexto de uso, la aplicación del análisis funcional de base microscópica permitió establecer que los artefactos bifaciales, los filos largos retocados y las lascas no presentan rastros de haber sido utilizados. Los filos se observan frescos y no hay evidencias de reactivación; aún se observan rastros tecnológicos producto de la formatización del artefacto que por lo general quedan obliterados cuando la pieza es utilizada en algún proceso de trabajo. Dichos artefactos no exhiben tampoco alteraciones post-depositacionales considerables que puedan explicar la ausencia de huellas de utilización.

Tabla 1: Estadística descriptiva sobre las características de las puntas.

\begin{tabular}{|c|c|c|c|}
\hline Estadística descriptiva & Peso & Ancho del pedúnculo & Angulo en vista plana \\
\hline $\mathrm{N}$ & 16 & 16 & 16 \\
\hline Media & 16,975 & 16,19 & 47,06 \\
\hline Varianza & 11,97 & 4,7 & 37,93 \\
\hline Desvío Estándar & 3,46 & 2,17 & 6,16 \\
\hline Mínimo & 9,8 & 14 & 35 \\
\hline Máximo & 25,4 & 20 & 60 \\
\hline Coeficiente de variación & 20,38 & 13,39 & 13,09 \\
\hline
\end{tabular}




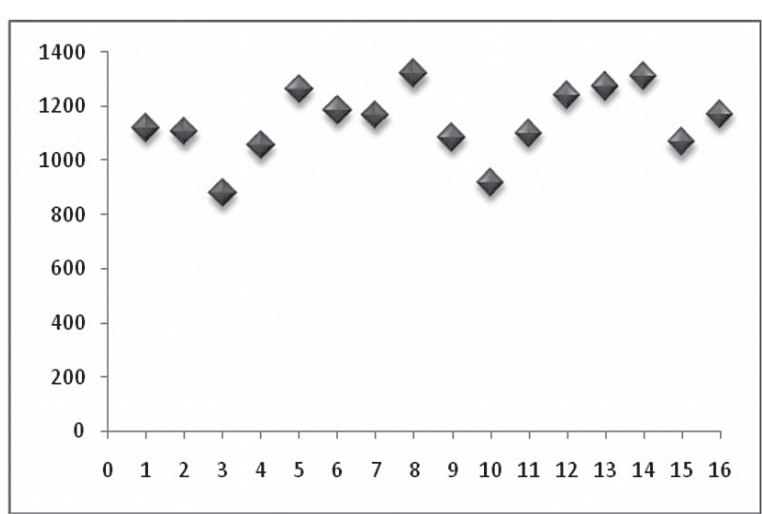

Fig. 11. Superficie del limbo en $\mathrm{mm}^{2}$.

El alisador presentaba estrías visibles macroscópicamente, sin embargo, el análisis microscópico no posibilitó determinar el material trabajado. Cabe mencionar que en instrumentos de características similares la aplicación del análisis funcional posibilitó determinar que fueron utilizados para pulir hueso (Mansur y Srehnisky 1997; Álvarez 2003).

Las puntas tampoco presentan el tipo de fractura característico que indica su utilización (Plisson y Geneste 1989). De acuerdo al modelo de asignación funcional y teniendo en cuenta: las características dimensionales del pedúnculo, la aerodinámica imperfecta y su tamaño, es posible suponer que estas puntas estuviesen destinadas a ser usadas como armas arrojadizas que entrarían al blanco por fuerza muscular. Es interesante observar que algunas piezas del ajuar exhiben ángulos en vista plana con valores superiores a $56^{\circ}$ Estos datos serían compatibles con el planteo de que algunas puntas podrían estar aún en etapa de manufactura.

Los artefactos óseos hallados son un punzón macizo confeccionado sobre diáfisis de metapodio de guanaco y varias cuentas de collar confeccionadas sobre diáfisis de huesos largos de algún ave de gran tamaño (petrel, albatros). Estas cuentas están decoradas con grabados en zig-zag y trazos cortos perpendiculares al eje de la pieza. El diseño es similar a otras cuentas analizadas en la región bajo estudio (Fiore 2006).

\section{DISCUSIÓN}

Hemos planteado que las acciones vinculadas al mundo funerario son prácticas sociales tendientes a reproducir la organización social. Las conductas

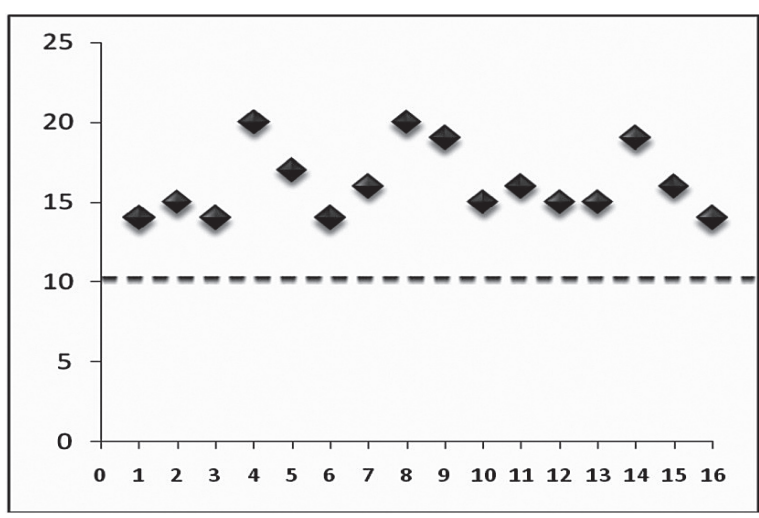

Fig. 12. Ancho de la base del pedúnculo.

relacionadas con la muerte son uno de los factores determinantes de la estructura del registro bioarqueológico regional y están en estrecha vinculación con la forma y la escala de las interacciones sociales de las poblaciones que las practicaban (ver Barrientos 2002 y bibliografía allí citada).

Tal como se dijo, el conocimiento de esas prácticas y conductas en la región del canal Beagle es aún escaso, los contextos mortuorios para los que se cuenta con dataciones seguras son pocos y sólo se extienden hasta unos 1.500 años atrás (Piana et al. 2006); aún así, su variabilidad resulta llamativa. El espectro del registro bioarqueológico incluye desde el abandono de los cuerpos sin ningún tipo de tratamiento en la disposición del cadáver (p. e. los párvulos hallados en Shamakush I y X y Ajej I, Tessone 2003, Piana et al. 2006), hasta situaciones como la aquí presentada: con múltiples eventos de depositación de cuerpos en el mismo rasgo de paisaje, excavación y acondicionamiento del espacio para disposición del cadáver y presencia de un ajuar funerario que incluye piezas sin utilización previa $y$, que interpretamos como confeccionadas ad hoc. También han sido variables otros aspectos vinculados tanto a la selección de los lugares de entierro (aleros, concheros, formaciones rocosas, en tierra) como a la forma de disponer los cuerpos (extendidos, flexionados) (Tessone 2003; Piana et al. 2006). La información etnohistórica revela en parte, también esa variabilidad (Bridges 1886; Hyades 1887; Gusinde 1937; Orquera y Piana 1999b, entre otros). En el sector occidental de los canales magallánico-fueguinos la tendencia es similar en lo que respecta a la diversidad de situaciones (San Román y Morello 2001). 
Si bien la secuencia relativa de los entierros del alero de Shamakush y su sincronicidad o diacronía están todavía en análisis, dos hechos resultan indiscutibles y son el centro de esta discusión: la recurrencia del uso de un elemento del paisaje para la disposición de cadáveres y la presencia de un ajuar asociado indudablemente a SHE 6 mucho más complejo que lo previamente conocido en la región.

De acuerdo con Ingold (1993) el carácter de un lugar depende de las actividades que allí los grupos humanos desarrollan y de las experiencias que remite a quienes lo utilizan. En este sentido, el afloramiento de Shamakush debe haber sido un rasgo de paisaje con particular carga simbólica pues allí se utilizaron por lo menos dos aleros para disposición de cadáveres, en uno de ellos se halló la mayor densidad de individuos hasta ahora conocidos en la región canal Beagle, uno de los cuales estaba asociado además al ajuar funerario más completo y elaborado recuperado hasta el presente.

En cuanto al análisis del ajuar, los resultados obtenidos en base a las líneas metodológicas implementadas revelan una serie de datos interesantes para la discusión tanto de las prácticas funerarias como en lo que respecta a las prácticas tecnológicas. En primer término, los objetos que conforman el ajuar fueron confeccionados utilizando materias primas y técnicas similares a aquellos que fueran recuperados en contextos domésticos con cronologías similares. Lo mismo ocurre con el diseño y la composición general del conjunto artefactual: están representados prácticamente la variedad completa de artefactos líticos presentes en la región. Estos datos posibilitan establecer una vinculación entre la esfera de lo doméstico y de lo ritual en los procesos productivos y en las decisiones y elecciones que subyacen a las modalidades de confección de artefactos. De esta manera las acciones y objetos de producción-consumo cotidianos se incorporan al mundo funerario.

Sin embargo también se trazan diferencias cuantitativas y cualitativas con el instrumental utilizado en la vida diaria. La inversión de trabajo desplegada en los objetos que conforman el ajuar es ostensiblemente diferente a la registrada hasta la fecha en cualquier otro conjunto conocido en la región. La mayoría de las piezas fueron manufacturadas mediante reducción bifacial que requiere mayor cantidad de operaciones técnicas, mayor conocimiento y habilidades motrices para su desarrollo (Aschero y Hocsman 2004). Asimismo el tamaño de algunas de las piezas que conforman este conjunto es notablemente superior que los hallados en contextos domésticos. Esta característica, sumada a la calidad de las rocas utilizadas, resulta significativa; el potencial que exhiben estos materiales para la talla dada su naturaleza metamórfica hace que resulte más costosa su obtención, fundamentalmente en lo que respecta a los módulos alargados. Es llamativo, no obstante, que tanto en los artefactos bifaciales como en los filos largos retocados hay piezas muy grandes y otras de tamaños similares a las recuperadas en los conchales.

También es notable el conjunto de puntas de arma hallado en este contexto. Todas ellas exhiben características dimensionales y morfológicas bastante homogéneas y sólo un tipo de las variedades registradas para esa época en la región está presente en este conjunto (Orquera y Piana 1999a; Álvarez 2007b). Por otra parte, constituyen los artefactos más numerosos del ajuar. Si consideramos el uso a los que estaban destinados este tipo de instrumentos, (la captura de presas), su frecuencia no constituye un dato menor, principalmente en el marco de sociedades donde la caza de animales juega un rol substancial para la continuidad del grupo. Por otro parte, es sugerente, la escasez de artefactos óseos en Shamakush Entierro dada su importancia en los contextos domésticos (Orquera y Piana 1999a).

En cuanto al uso ocurre algo similar, con excepción del alisador, ninguna de las piezas presenta rastros de uso que posibiliten determinar su utilización incluso algunos parecieran que están aún en proceso de confección. Estas observaciones permiten sugerir que la mayoría de los artefactos habrían sido confeccionados para ser incorporados como ajuar mortuorio. Este hecho sumado a las diferencias arriba trazadas con respecto a los conjuntos domésticos reforzarían esta idea.

Los análisis aquí presentados han demostrado que los objetos generados dentro de la esfera tecnológica no constituyen sólo elementos utilitarios: los procesos de producción material y sus productos resultantes son estructuras materiales y simbólicas a través de las cuales el mundo es percibido, transformado y recreado (Álvarez 2003).

Más allá que aún falta mucho por indagar en la problemática de las prácticas mortuorias de los 
grupos cazadores-recolectores-pescadores del canal Beagle, lo sobresaliente del caso aquí presentado es que en todo sentido constituye el extremo del abanico de variabilidad registrado en la región. En el alero de Shamakush se conjugan una serie de rasgos que hacen de éste el contexto funerario conocido más costoso en términos de tiempo y recursos invertidos en relación a una práctica funeraria. Los elementos clave son: la recurrencia de entierros en un mismo espacio, la existencia de dos entierros más en otro alero de la misma geoforma, las posibles evidencias de cremación y la preparación del espacio donde sería depositado uno de los cuerpos con su ajuar.

Sin lugar a dudas los factores determinantes de tal variabilidad deben ser múltiples y muy complejos. Podrían variar desde aspectos situacionales, como la estación del año en que ocurriera la muerte y la presencia o no de suelos congelados, hasta aspectos de orden social, como el establecimiento de diferentes formas de segmentación interna a los grupos basadas en categorías de edad, género o acceso diferencial a algún tipo de recurso sea económico o ideológico.

Desde la perspectiva que aceptamos, los objetos incluidos en forma de ajuar así como la selección de los lugares para depositación de cadáveres, su disposición y otras manifestaciones materiales asociados al enterramiento (v.g. tamaño y forma de fosas), son expresión material de elecciones y decisiones de los grupos sociales y constituyen un mensaje activo para el mundo de los vivos en los que se incluyen aspectos económicos y simbólicos. En el estado actual del conocimiento regional aún no podemos dar más precisiones sobre las causas que generaron esas decisiones. Resulta necesario profundizar esta línea de investigación para analizar de qué modo ese mensaje se está reflejando en el registro arqueológico y cuáles son las tendencias temporales de los distintos modos de inhumación. Aún así, Shamakush Entierro se encuentra en un extremo de la variabilidad conocida y constituye un llamado de atención sobre la complejidad social de la región hasta ahora aceptada.

\section{AGRADECIMIENTOS}

Al Consejo Nacional de Investigaciones Científicas y Tecnológicas y a la Agencia Nacional de Promoción Científica y Tecnológica quienes han financiado estas investigaciones. A los revisores anónimos del manuscrito cuyas sugerencias han sido sumamente valiosas.

A nuestros compañeros de equipo por las experiencias compartidas a través de estos años de trabajo.

\section{BIBLIOGRAFÍA}

ÁLVAREZ M. R. 2003. Organización tecnológica en el canal Beagle: el caso de Túnel I (Tierra del Fuego). Tesis doctoral, Universidad de Buenos Aires. Ms.

ÁlVAREZ, M. 2007a. Procesos de producción y uso de instrumentos bifaciales entre los grupos canoeros del canal Beagle. En Arqueología de Fuego-Patagonia. Levantando piedras, desenterrando huesos... y develando arcanos: 247-255 Ediciones CEQUA. Chile.

ÁlVAREZ, M. 2007b. Puntas de arma del extremo sur de patagonia: algunas consideraciones sobre diseño y contexto de uso. XVI Congreso Nacional de Arqueología Argentina. MS

ÁLVAREZ, M. y D. FIORE 1993. La arqueología como ciencia social: apuntes para un enfoque teórico-epistemológico. Boletín de Antropología Americana 27:21-38.

ASCHERO, C. y S. HOCSMAN. 2004. Revisando cuestiones tipológicas en torno a la clasificación de artefactos bifaciales. En Temas de Arqueología. Análisis Lítico, compilado por M. Ramos, A. Acosta y D. Loponte pp. 7-25. Universidad Nacional de Luján.

ASPILLAGA, E. y C. OCAMPO. 1996. Restos Óseos Humanos de la Isla Karukinka (Seno Almirantazgo) Informe Preliminar. Anales del Instituto de la Patagonia 24:153-161.

ASPILLAGA, E. C. OCAMPO y P. RIVAS. 1999. Restos Óseos Humanos de Contextos Arqueológicos del Área de Isla Navarino: Indicadores de Estilos de Vida en Indígenas Canoeros. Anales del Instituto de la Patagonia 27:123-135.

BARRIENTOS G. 2002. The archaeological analysis of deathrelated behaviors from an evolutionary perspective. En Perspectivas Integradoras entre Arqueología y Evolución (pp. 221-253). Editado por Martínez G. y J. L. Lanata. INCUAPA, Olavarría.

BENDER, B. 1985. Emergent tribal Formations in the American Midcontinent. American Antiquity 50: 52-62.

BOURDIEU, P. 1977. Outline of a Theory of Practice. Cambridge University Press.

BRIDGES, T. 1886. El confín sur de la República: la Tierra del Fuego y sus habitantes. Boletín del Instituto Geográfico Argentino VII: 200-212. 
FIORE, D. 2006. Puentes de agua para el arte mobiliar: la distribución espacio-temporal de artefactos óseos decorados en Patagonia meridional y Tierra del Fuego. Cazadores-Recolectores del Cono Sur. Revista de arqueología. I. 137-147.

GUICHÓN R. 2000. Agenda para una evaluación en la Antropología Biológica de Patagonia Austral. En Desde el País de los Gigantes. Perspectivas arqueológicas en Patagonia, Tomo I, pp. 99-106. UNPA, Río Gallegos, Argentina.

GUICHÓN R., L. BORRERO, A. PRIETO, P. CÁRDENAS y R. TYKOT. 2001. Nuevas determinaciones de isótopos estables para Tierra del Fuego. Revista Argentina de Antropología Biológica 3 (1):113-126.

GUSINDE, M. 1937. Die Feuerland-Indianer, vol. II: Die Yamana. Mödling. 1500 págs. [Las citas están tomadas de la traducción del castellano: CAEA, 1986, 3 volúmenes, Buenos Aires].

HYADES, P. 1887. Etnographie des Fuéguiens. Bulletins de la Societé d'Anthropologie de Paris (tercera serie) X: 327-345.

INGOLD, T. 1993. The temporality of the landscape. World Archaeology 25 (2): 152-174.

KOZAMEH L. F., J. E. BARBOSA y E. TAMUCH. 2002. Tierra del Fuego. Un poblador tardío del canal Beagle. Análisis esqueletal y dentario. Resumen presentado en las Quintas Jornadas de Arqueología de la Patagonia p. 15. Buenos Aires, 27 al 31 de mayo del 2002.

LEGOUPIL, D. 1993-94 El archipiélago del cabo de Hornos y la costa sur de la isla Navarino: poblamiento y modelos económicos. Anales del Instituto de la Patagonia 22:101-121. Chile.

MANSUR M. E. 1999. Análisis funcional de instrumentos líticos: problemas de formación y deformación de rastros de uso. En: Actas del XII Congreso Nacional de Arqueología Argentina, pp. 355-366. La Plata.

MANSUR, M. E. y R. SREHNISKY. 1997. El alisador basáltico de Shamakush I: microrrastros de uso mediante el análisis de imágenes digitalizadas. Relaciones XXI.

OCAMPO C., E. ASPILLAGA y P. RIVAS. 2001. Entierros en Terrazas Altas, Ensenada Villarino (Sitio $N^{\circ} 130$ isla Navarino). Informe Proyecto FONDECYT 1980654. MS.

ORQUERA L. A. y PIANA E. L. 1986. Normas para la descripción de piedra tallada. Contribución Científica № . 1, Publicación Especial, Centro Austral de Investigaciones Científicas (CONICET), Ushuaia.

ORQUERA, L. y E. PIANA. 1997. El sitio Shamakush I (Tierra del Fuego, República Argentina). Relaciones de la
Sociedad Argentina de Antropología XXI: 215-265. Buenos Aires.

ORQUERA, L. y E. PIANA. 1999a. Arqueología de la región del Canal del Beagle (Tierra del Fuego, República Argentina). Publicaciones de la Sociedad Argentina de Antropología.

ORQUERA L. A. y PIANA 1999b. La vida material y social de los Yámana. Eudeba, Buenos Aires.

ORQUERA L. A. y PIANA 2006. La adaptación al litoral sudamericano sudoccidental: qué es y quiénes, cuándo y dónde se adaptaron. Relaciones de la Sociedad Argentina de Antropología XXX (2005):11-32.

ORQUERA L. A.; E. PIANA; M. ÁlVAREZ; D. FIORE; M. VÁZQUEZ M.; A. ZANGRANDO; A.TESSONE y A. Tivoli. 2006. El Proyecto Arqueológico Canal Beagle. En Arqueología de la Costa Patagónica. Perspectivas para la conservación. Editado por Cruz I y Caracotche S. 266-290 Universidad Nacional de la Patagonia Austral y Secretaría de Cultura de la provincia de Chubut.

PÉREZ-PÉREZ A. 1996. Aborigines from Tierra del Fuego: human adaptation to a harsh environment. En Notes on populational significance of paleopatological conditions: health, illnes and death in the past, pp.107-122. Compilador Pérez-Pérez A., Fundación Uriach 1838, Barcelona, España.

PIANA E.; A. TESSONE y A. ZANGRANDO. 2006. Contextos mortuorios en la región del canal Beagle... del hallazgo fortuito a la búsqueda sistemática. Magallania 34 (1): 87-101 Punta Arenas, Chile.

PIANA E. y M. VÁZQUEZ. 2005. El Sitio Shamakush VIII.: puntualizaciones sobre el uso de recursos y la gestión del asentamiento en el canal Beagle Aceptado para publicación Actas XV Congreso Nacional de Arqueología Argentina.

PIANA E. M. VÁZQUEZ y M. ÁLVAREZ. 2007. El Sitio Ajej I: Excavación de Rescate en la costa del Canal Beagle. Arqueología Argentina en los inicios de un nuevo siglo. Tomo I. Publicación del XIV Congreso Nac. de Arqueología Argentina: 345-356. Rosario.

PIANA E. M. VÁZQUEZ y M. ÁLVAREZ. 2008. El sitio Ajej I: un aporte a la variabilidad de estrategias de los canoeros fueguinos. Runa № 29 en prensa.

PIANA, E., M. VÁZQUEZ y N. RÚA. 2004. Mischiuen I. Primeros resultados de una excavación de rescate en la costa norte del canal Beagle. En Contra Viento y Marea. Arqueología de Patagonia, compilado por M. Civalero, P. Fernández y G. Guraieb, pp. 815-832. Instituto Nacional de Antropología y Sociedad Argentina de Antropología 
PLISSON, H. y J. M. GENESTE. 1989. Analyse technologiques des pointes à cran Solutréennes du Placard (Charente), du Fourneu du Diable, du Pech de la Boissière et de Combe Saunière (Dordogne). Paléo 1:65-106.

PRIETO, A. y P. CÁRDENAS. 2001. Ajuar de Cueros en el Entierro Canoero en el Archipiélago de Tierra del Fuego. Anales del Instituto de la Patagonia 29:183-188.

RATTO N. 2003. Estrategias de Caza y Propiedades de Registro Arqueológico en la Puna de Chaschuil (Dpto. de Tinogasta, Catamarca, Argentina. Tesis doctoral, Universidad de Buenos Aires. Ms.

SAN ROMÁN, M. y F. MORELLO. 2001. Canal Maule: Nuevos antecedentes sobre Prácticas Funerarias en el Archipiélago Fueguino. Anales del Instituto de la Patagonia 29:149-161.

SCHLANGER, N. 1994. Mindful technology: unleashing the chaine operatoire for an archaeology of mind. The ancient mind. Elements of cognitive archaeology. Editado por C. Renfrew and E. Zubrow, 143-151. Cambridge University Press.

TERRADAS, X. 1996. La gestió dels recursos minerals entre les comunitatas caçadores-recol-lectores. Vers una representació de les estratègies de proveïment de matèries primeres. Tesis de Doctorado. Universitat Autonoma de Barcelona.

TESSONE A. 2003. Conductas Mortuorias en El Canal Beagle. Tesis de Licenciatura en Facultad de Filosofía y Letras, Universidad de Buenos Aires. MS.

VAN DE MAELE M. 2000. Enterratorios Yámana: Relato de las Ultimas Memorias en Puerto Williams. En MUSEOS № 24: 1-6, Chile.

VAZQUEZ M., M. ALVAREZ Y E. PIANA. 2007. Variabilidad en las prácticas mortuorias entre los cazadores-recolectores del canal Beagle: el caso de Shamakush enterratorio. Tras las huellas de la materialidad. Número Especial de la Revista Pacarina (2): 79-85.

VILA MITJA A. 2004. Proyectos etnoarqueologicos en Tierra del Fuego (Argentina). En Bienes Culturales no 3: 193-200. Madrid.

VILA MITJA A., O. VICENTE, O. de CASTRO, A. CASAS, J. ESTÉVEZ, J. A. BARCELÓ y L. MAMELI. 2002. Informe de la campaña de excavaciones inserta en el proyecto "Sociedad y Ritual de los últimos cazadores-recolectores del canal Beagle (Tierra del Fuego, Argentina)". Ministerio de Educación y Cultura de España.MS. 
